\title{
Patients with Premenstrual Dysphoric Disorder have Increased Startle Response Across both Cycle Phases and Lower Levels of Prepulse Inhibition During the Late Luteal Phase of the Menstrual Cycle
}

\author{
Kristiina Kask,', Maria Gulinello², Torbjörn Bäckström, Mark A Geyer ${ }^{4}$ and Inger Sundström-Poromaa' \\ 'Department of Women's and Children's Health, Uppsala University, Uppsala, Sweden; ${ }^{2}$ Dominick P. Purpura Department of Neuroscience, \\ Albert Einstein College of Medicine, New York, USA; ${ }^{3}$ Department of Clinical Science, Obstetrics and Gynecology, Umeå University, Umeå, \\ Sweden; ${ }^{4}$ Department of Psychiatry, University of California, San Diego, CA, USA
}

\begin{abstract}
Patients with premenstrual dysphoric disorder (PMDD) experience their most intense symptoms during the late luteal phase. The aim of the current study was to compare acoustic startle response and prepulse inhibition in PMDD patients and controls during the follicular and late luteal phases of the menstrual cycle. Following two months of prospective daily ratings on the Cyclicity Diagnoser scale, 30 PMDD patients and 30 asymptomatic controls, between the ages of 20 and 46, were included in the study. The eyeblink component of the acoustic startle reflex was assessed using electromyographic measurements of $\mathrm{m}$. orbicularis oculi. Twenty pulse-alone trials (I I $5 \mathrm{~dB}$ $40 \mathrm{~ms}$ broad-band white noise) and 40 prepulse-pulse trials were presented. The prepulse stimuli consisted of a $115 \mathrm{~dB} 40 \mathrm{~ms}$ noise burst preceded at a $100 \mathrm{~ms}$ interval by $20 \mathrm{~ms}$ prepulses that were $72,74,78$, or $86 \mathrm{~dB}$. PMDD patients had a significantly higher startle response than controls during both phases of the menstrual cycle $(p<0.05)$. PMDD patients exhibited lower levels of prepulse inhibition with $78 \mathrm{~dB}$ and $86 \mathrm{~dB}$ prepulses compared to control subjects in the luteal $(p<0.0 \mathrm{I})$ but not in the follicular phase. Whereas control subjects displayed increased PPI during the late luteal phase compared to the follicular phase $(p<0.0 \mathrm{I})$, PPI magnitude remained unchanged in PMDD patients between cycle phases. Relative to controls, PMDD patients displayed increased startle reactivity across both menstrual cycle phases and deficits in prepulse inhibition of acoustic startle during the late luteal phase. These findings are consistent with an altered response to ovarian steroids among PMDD patients.
\end{abstract}

Neuropsychopharmacology (2008) 33, 2283-2290; doi:I0. I038/s..npp. I 30 I599; published online 17 October 2007

Keywords: startle response; prepulse inhibition; premenstrual dysphoric disorder; menstrual cycle; estradiol; progesterone

\section{INTRODUCTION}

The premenstrual dysphoric disorder (PMDD) is characterized by a recurrent cluster of physical and negative mood symptoms. Symptoms appear during the luteal phase of the menstrual cycle and disappear within a few days after the onset of menstrual bleeding (Backstrom et al, 2003). Symptoms occur only during ovulatory menstrual cycles in the presence of a corpus luteum (Hammarback and Backstrom, 1988; Hammarback et al, 1991), or during progesterone administration (Bjorn et al, 2002, 2003; Hammarback et al, 1985). Several neurotransmitter systems, the serotonergic (Parry, 2001), the noradrenergic (Eriksson

*Correspondence: Dr K Kask, Department of Women's and Children's Health, Uppsala University, University Hospital, Uppsala SE-75I 85, Sweden, Tel: 46/861/3174, Fax: 4618559775, E-mail: kristiina. kask@kbh.uu.se

Received 28 June 2007; revised 17 September 2007; accepted 19 September 2007 et al, 1994), and the GABAergic systems (Epperson et al, 2002; Sundstrom et al, 1998, 1997a, b) have been suggested to play part in the pathogenesis of the disorder, however, the biological events underlying the surfacing of symptoms during the luteal phase remain unclear.

In addition to negative mood symptoms, objective manifestations of physiological arousal, such as the acoustic startle response, are also influenced by estradiol and progesterone (Byrnes et al, 2007; Gulinello et al, 2003; Toufexis et al, 1999; Vaillancourt et al, 2002; Van den Buuse and Eikelis, 2001). The acoustic startle response is increased in an animal model of PMDD (Gulinello et al, 2003), and was recently also shown to be increased in the luteal phase of PMDD patients (Epperson et al, 2007). The acoustic startle reflex (ASR) is a withdrawal reflex to sudden or noxious auditory stimuli, which can be measured as an eyeblink in humans or as a whole body response in laboratory animals (Davis, 1980). This paradigm is a useful bridge between preclinical and human data, since it has a similar circuitry and pharmacology in humans as it has in 
animals (Davis, 1980; Koch, 1999). Furthermore, ASR is clinically relevant for PMDD patients, since altered acoustic startle responses have been demonstrated in patients with anxiety and depressive disorders (Allen et al, 1999; Morgan et al, 1996; Pissiota et al, 2003) and in animal models of these disorders (Davis et al, 1997; Plappert and Pilz, 2002; Schwegler et al, 1997; Stohr et al, 1999) including a rodent model of PMDD (Gulinello et al, 2003; Gulinello and Smith, 2003). In addition, the acoustic startle response is also regulated by the agents thought to be critical to the etiology PMDD symptoms, notably progesterone fluctuations and underlying alterations in inhibitory neurotransmission via the $\mathrm{GABA}_{\mathrm{A}}$ receptor (Toufexis et al, 2004).

We predicted that subjects with PMDD would have higher ASR than asymptomatic controls in the luteal phase, based on prior studies of ASR in PMDD patients (Epperson et al, 2007), and on a working model of the underlying mechanisms of the etiology of negative mood symptoms. In women with PMDD, symptoms occur in the luteal phase of the menstrual cycle (Backstrom et al, 2003) in close correlation to progesterone fluctuations. Although estrogen and other hormones cannot be ruled out as influences in PMDD, several lines of evidence suggest that fluctuations in progesterone and its neuroactive metabolites are necessary for PMDD symptoms. In humans, negative mood symptoms can be prevented by suppression of corpus luteum formation, which thus suppresses the high progesterone levels typifying the luteal phase (Sundstrom et al, 1999). Animal models of PMDD, in which the levels of progesterone and estrogen can be manipulated directly, also indicate that it is administration of progesterone (or its neuroactive metabolite, allopregnanolone) that is associated with anxiety-like behaviors (Gallo and Smith, 1993; Moran and Smith, 1998; Smith et al, 1998a,b) including increased ASR (Gulinello et al, 2003; Gulinello and Smith, 2003). The fact that anxiety-like behavior also occurs among pre-pubertal female rodents in the progesterone withdrawal model reinforces the primary role of progestins in the etiology of negative mood symptoms.

Sensorimotor gating can also assessed by measuring prepulse inhibition (PPI) of the startle response, which is thought to reflect an individual's ability to screen or 'gate' sensory stimuli. The PPI paradigm uses a weak, nonstartling acoustic stimulus (the prepulse) that typically decreases the reflexive eyeblink response (startle) produced by the subsequent startling stimulus (the pulse). The sensorimotor gating of the ASR is also subject to regulation by the putative causative agents of PMDD, including steroid hormones and dysregulation of inhibitory neurotransmission. Sensorimotor gating is regulated by $\mathrm{GABA}_{\mathrm{A}}$ receptors in several relevant brain regions, notably the amygdala and the bed nucleus of the stria terminalis (BNST) (Lee and Davis, 1997; Yee et al, 2005; Hauser et al, 2005). Ovarian steroids also appear to influence PPI because women have lower levels of PPI than men (Swerdlow et al, 1993) and because PPI varies across the menstrual cycle in healthy women (Jovanovic et al, 2004; Swerdlow et al, 1997).

Given the increased vulnerability to exposure and withdrawal from ovarian steroids and the effects of these steroids on startle response and PPI of startle, the primary aim of the current study was to compare startle responding and PPI in patients with PMDD and asymptomatic controls during the follicular and late luteal phases of the menstrual cycle.

\section{MATERIALS AND METHODS}

\section{Subjects}

Eighty-seven women complaining of premenstrual symptoms were screened for inclusion in the study. Of these, 30 women fulfilled criteria for PMDD. Hence, 30 PMDD patients and 30 asymptomatic controls, between the ages of 20 and 46, were included in the study. Patients were recruited among women seeking help for premenstrual symptoms at the outpatient ward of the Department of Obstetrics and Gynaecology, Uppsala University Hospital and from newspaper advertisement.

Included patients met the criteria for PMDD diagnosis, defined in the Diagnostic and Statistical Manual of Mental Disorders, fourth edition (DSM-IV, 1994). Diagnosis was based on daily, prospective symptom ratings on the Cyclicity Diagnoser (CD) scale during two cycles prior to inclusion (Sundstrom et al, 1999). The CD scale consists of nine negative mood parameters (depression, decreased interest in usual activities, fatigue, irritability, tension, mood swings, lability, difficulties in concentrating, and sleeping disturbances), two positive mood parameters (cheerfulness, energy), and four somatic symptoms (food cravings, swelling, breast tenderness, and menstrual bleeding). In addition, the $\mathrm{CD}$ scale contains a score for measuring the everyday social functioning and work performance. The CD scale is a Likert scale ranging from $0-8$, with 0 as complete absence of a particular symptom, and 8 as the maximal severity of the symptom. Patients were considered to have PMDD if they had a $100 \%$ increase in at least five symptoms during seven premenstrual days compared to seven mid-follicular days, associated with a clinically significant social and occupational impairment. The threshold score for impact on daily life was set at a score of four or more for more than two days during the luteal phase. This score indicated that subjects avoided social interaction during these days. All patients displayed at least one week of sparse symptoms (scores less than two) in the mid-follicular phase.

Asymptomatic controls were physically healthy women between the ages of 20 and 46 with regular menstrual cycles and no self-report of premenstrual symptoms. According to the daily prospective ratings, control subjects displayed no significant cyclicity in mental symptoms between the follicular and luteal phase and impact on daily life never exceeded a score of two during the luteal phase (no impact or only the patient notices any symptoms).

The exclusion criteria were hearing deficiencies (see below), treatment with any hormonal compounds, treatment with benzodiazepines or other psychotropic drugs including serotonin reuptake inhibitors, and presence of any ongoing psychiatric disorder. The presence of psychiatric disorders was evaluated using a structured psychiatric interview, the Swedish version of Mini International Neuropsychiatry Interview (M.I.N.I.), based on DSM-IV and ICD-10 (Sheehan et al, 1998). All subjects had negative pregnancy tests.

A brief hearing screening using an audiometer (Madsen Midi-mate 622, GN Otometrics, Taastrup, 
Denmark) confirmed that all subjects were able to detect $40 \mathrm{~dB}$ tones at 500,1000 , and $6000 \mathrm{~Hz}$.

The women gave written informed consent prior to inclusion in the study. The study procedures were in accordance with ethical standards for human experimentation, and the Independent Research Ethics Committee, Uppsala University approved the study.

\section{Study Protocol}

Measurements were made twice during the menstrual cycle: once in the mid-follicular phase (6-12 days after the onset of menstrual bleeding) and once in the late luteal phase (1-7 days prior to the onset of menstruation). Half of the subjects were scheduled to start in the follicular phase, whereas the remaining subjects started in the luteal phase to avoid test order effects across the menstrual cycle. Luteal phase testings were scheduled according to the positive LH assay (Clearplan, Unipath, Bedford, UK) to coincide with late luteal phase (postovulatory days 8-13). The luteal phase intervals were chosen to correspond with maximum severity of mood symptoms rather than peak progesterone levels. Monitoring of luteal phase was confirmed by progesterone serum concentrations and records on the next menstrual bleeding were provided by the ratings on the $\mathrm{CD}$ scale.

Testing was carried out at the research laboratory at the Department of Women's and Children's Health, Uppsala University. Each subject was seated in a comfortable chair in a quiet room and was unable to see the recording equipment. During the test session subjects sat upright and were directed to look straight ahead and to stay awake.

Before the test session blood samples for progesterone and estradiol serum concentrations were taken.

\section{Startle Response}

The eyeblink component of the ASR was assessed using EMG measurements of musculus orbicularis oculi. The delivering of the acoustic startle stimuli and the recording of the eyeblink response were controlled by a commercial startle system (SR-HLAB, San Diego Instruments, San Diego, CA). Acoustic startle stimuli were delivered binaurally by telephonic headphones (TDH-39-P, Maico, Minneapolis, MN, USA). The sound was calibrated with a Quest Electronics meter (model 210 Quest Technologies, Oconomov, WI). After the skin was scarified with alcohol, two miniature silver/silver chloride electrodes (In Vivo Metric, Healdsburg, CA, USA), with a small amount of electrode gel (Sigma gel, In Vivo Metric) were positioned below the subject's right eye, over the orbicularis oculi muscle. A ground electrode was placed in the center of the forehead. Electrode impedances were measured and confirmed to be less than $5 \mathrm{kOhm}$. The EMG was filtered $(100-1000 \mathrm{~Hz})$, digitized at $1 \mathrm{kHz}$ and analyzed by the EMG startle response software.

In order to allow subjects to acclimatize to the test situation, the ASR test session began with a five-minute acclimation period, with a background $70 \mathrm{~dB}$ white noise delivered by the headphones. Following this adaptation period, a series of trials were administered and the startle responses recorded. Throughout the session, a background $70 \mathrm{~dB}$ white noise continued in between the trials. The test session included four trial blocks. Block 1 consisted of five pulse-alone trials $(115 \mathrm{~dB} \quad 40 \mathrm{~ms}$ broad-band white noise), which were used for measurement of baseline startle response. Blocks 2 and 3 each consisted of 25 trials, containing 5 pulse-alone and 20 prepulse-pulse trials presented in pseudorandom order. The prepulse stimuli consisted of a $115 \mathrm{~dB} 40 \mathrm{~ms}$ noise burst preceded at a $100 \mathrm{~ms}$ interval by prepulses ( $20 \mathrm{~ms}$ noise bursts) that were $2,4,8$, $16 \mathrm{~dB}$ above the $70 \mathrm{~dB}$ background noise $(\mathrm{PP} 1=72 \mathrm{~dB}$; $\mathrm{PP} 2=74 \mathrm{~dB} ; \quad \mathrm{PP} 3=78 \mathrm{~dB} ; \mathrm{PP} 4=86 \mathrm{~dB}$ ). The last block consisted of five pulse-alone trials, which allowed a measure of within-test habituation. The inter-trial interval was variable, averaging $30 \mathrm{~s}$.

\section{Hormone Assays}

Progesterone and estradiol were analyzed on Immulite 1000 (DPC, Los Angeles, CA, USA). For the estradiol assay the measure interval was 73-7300 pmol/l. Estradiol intra-assay coefficient of variation was $9.5 \%$ at $426 \mathrm{pmol} / \mathrm{l}$ and $6.3 \%$ at $1760 \mathrm{pmol} / \mathrm{l}$. Progesterone intra-assay coefficient of variation was $16 \%$ at $2.9 \mathrm{nmol} / 1$ and $6.3 \%$ at $25.1 \mathrm{nmol} / 1$.

\section{Statistical Analyses}

Patients with negligible startle responses (mean amplitude $<10 \mu \mathrm{V}$ ) were considered as nonresponders. According to this definition, three PMDD patients and three controls were considered to be nonresponders and were removed from the analyses.

Peak startle amplitudes were measured automatically within $20-150 \mathrm{~ms}$ following the onset of the startle stimulus. A zero response score was given if no response was detectable, according to the default criteria provided by the software: (1) the peak startle response occurred outside the $20-150 \mathrm{~ms}$ time frame; (2) a baseline shift exceeded 40 arbitrary units; and (3) a startle response was 25 arbitrary amplitude units or less. An arbitrary unit corresponded to $0.076 \mu \mathrm{V}$. Less than $6.3 \%$ of responses were scored as zero responses, evenly distributed between cycle phases and groups.

Startle magnitude was defined as the total amplitude of all trials with response/total number of trials. Habituation of startle response (HAB) was calculated as the reduction in startle amplitude between the first and last blocks of pulsealone trials $(\% \mathrm{HAB}=100 \times($ first block-last block $) /$ first block). PPI in blocks 2 and 3 was computed as the percentage reduction in peak magnitude of startle on pulse-alone (PA) trials by the formula,

$\mathrm{PPI}=100 \times\left(M_{\mathrm{PA}}-M_{\mathrm{PP}}\right) / M_{\mathrm{PA}}$, where $M_{\mathrm{PA}}$ is a mean magnitude of pulse-alone and $M_{\mathrm{PP}}$ is a magnitude of prepulse-pulse trials.

Startle response and PPI were compared between groups by use of three-way ANOVA with repeated measures. Since no interactions or main effects of block were observed $(\mathrm{F}<2.20, p>0.10)$, data were collapsed across blocks 2 and 3 for PPI analyses.

Within subjects factors in the ANOVA analyses were cycle phase (follicular vs luteal phase) prepulse intensity (PPI 1-4) or startle response (first block vs last block), whereas group (PMDD patients $v s$ control subjects) was used as the between-groups factor in the analyses. Whenever the three-way ANOVA indicated a significant main effect or interaction, follow-up ANOVAs were made to 
determine at which level the significant finding occurred. Additional post hoc tests for prepulse intensity interactions were obtained by Tukey HSD Test.

To assess if symptom severity during the actual luteal phase (during which PMDD patients were tested) influenced ASR and PPI, PMDD patients were grouped according to their daily symptom ratings on the CD scale. In 22 PMDD patients with complete late luteal phase scorings (day -1 to day -7 ) during the test cycle a median split was performed distinguishing subjects with high levels of anxiety and high levels of depression. The median split was based on mean summarized anxiety and irritability scores for the high/low anxiety groups and on mean depression scores for the high/ low depression groups. Accordingly, 11 PMDD patients were defined as high-anxiety or high-depression patients and 11 subjects were defined as low-anxiety or low-depression patients. As there was a substantial overlap between the high-anxiety and the high-depression groups (8 of 11 subjects were high anxiety and high depression patients, whereas 9 of 11 subjects were low anxiety and low depression patients), a third group of 8 high anxiety/high depression patients and 9 low anxiety/low depression patients were formed.

Demographic variables were compared between groups by independent $t$-tests and chi-square tests. For intraindividual comparisons between menstrual cycle phases of hormone levels in each respective group, the Wilcoxon matched-pairs signed-ranks test was performed. Differences between groups in hormone levels were evaluated by the Mann-Whitney $U$-test. Correlations between estradiol and progesterone and mean PPI and startle response were made with Pearson's correlation coefficient.

The SPSS statistical package was used for the analyses. $P$-values of less than 0.05 were considered to be statistically significant. Data are presented as mean \pm SEM, unless otherwise stated.

\section{RESULTS}

Two PMDD patients and three controls withdrew from the study after participating in the follicular phase (one PMDD patient and two controls) or the luteal phase (one PMDD patient and one control). Reasons for withdrawing were detected pregnancy, aversive test situation, and personal reasons. These subjects have been kept in the analyses as far as possible. Demographic data of the study group are given in Table 1.

Plasma levels of estradiol and progesterone in each group and cycle phase are given in Table 2. Steroid levels were not significantly different between PMDD patients and control subjects in either cycle phase and, as expected, serum concentrations of progesterone increased in the luteal phase compared to the follicular phase in both groups.

Control subjects and PMDD patients did not differ with respect to the timing of testing for follicular phase (cycle day $7.5 \pm 0.4$ vs $8.5 \pm 0.3$ ) or luteal phase (cycle day $-6.6 \pm 0.6 v s-5.0 \pm 0.6)$. All patients were considered to have had ovulatory cycles when tested.

\section{Acoustic Startle Response (ASR)}

PMDD patients had a significantly higher startle response than controls in all phases of the menstrual cycle. Thus,
Table I Demographic Data and Physical Characteristics of the Study Group

\begin{tabular}{lcc}
\hline & PMDD (n=27) & Controls $(\boldsymbol{n}=\mathbf{2 7})$ \\
\hline Age $(\mathrm{y})$ & $37.8 \pm 5.5$ & $34.8 \pm 8.2$ \\
Body mass index $\left(\mathrm{kg} / \mathrm{m}^{2}\right)$ & $24.4 \pm 3.5$ & $23.0 \pm 3.5$ \\
Married or cohabiting (\%) & $27(100 \%)$ & $27(100 \%)$ \\
Children ( $\mathrm{n})$ & $1.6 \pm 1.3$ & $1.2 \pm 1.2$ \\
University/college & $13(48.1 \%)$ & $21(77.8 \%)$ \\
education $(\%)$ & & $17(63.0 \%)$ \\
Employed $(\%)$ & $18(66.6 \%)$ & $7(25.9 \%)$ \\
Tobacco users & $7(25.9 \%)$ & \\
\hline
\end{tabular}

Abbreviation: PMDD, premenstrual dysphoric disorder.

Data are presented as mean \pm SD or $n(\%)$.

Table 2 Plasma Levels of Estradiol (pmol/l) and Progesterone $(\mathrm{nmol} / \mathrm{l})$ in the Follicular and the Luteal Phase of the Menstrual Cycle in 27 Women with PMDD and 27 Controls

\begin{tabular}{lcclcc}
\hline & \multicolumn{2}{c}{ PMDD $(\mathbf{n}=\mathbf{2 7})$} & & \multicolumn{2}{c}{ Controls $(\mathbf{n}=\mathbf{2 7})$} \\
\cline { 2 - 3 } \cline { 5 - 6 } & $\begin{array}{c}\text { Follicular } \\
\text { phase }\end{array}$ & $\begin{array}{c}\text { Luteal } \\
\text { phase }\end{array}$ & & $\begin{array}{l}\text { Follicular } \\
\text { phase }\end{array}$ & $\begin{array}{c}\text { Luteal } \\
\text { phase }\end{array}$ \\
\hline $\begin{array}{l}\text { Estradiol } \\
\text { (pmol/l) }\end{array}$ & $185 \pm 162$ & $201 \pm 234$ & & $154.5 \pm 142$ & $224.1 \pm 148$ \\
$\begin{array}{l}\text { Progesterone } \\
\text { (nmol/l) }\end{array}$ & $0.9 \pm 1.1$ & $23.7 \pm 15.4 * * *$ & & $1.2 \pm 2.1$ & $29.1 \pm 18.2 * * * * 1$ \\
\hline
\end{tabular}

Abbreviation: PMDD, premenstrual dysphoric disorder.

**** Difference from follicular phase $P<0.001$, Wilcoxon signed ranks test.

there was a significant difference between PMDD patients and control subjects on startle reactivity to the first block of pulse-alone trials (main effect of group $\mathrm{F}(1,47)=4.18$; $p<0.05$, but there was no phase, or phase by group interaction for the startle response, Figure 1. Percent habituation throughout the test session did not differ between groups in either cycle phase (PMDD patients follicular phase $37.6 \% \pm 5.8$, luteal phase $47.8 \% \pm 5.0$, control subjects follicular phase $54.6 \% \pm 8.5$, luteal phase $61.5 \% \pm 7.1)$.

ASR was not influenced by the anxiety symptoms or depressive symptoms experienced by the PMDD patients during the luteal phase in which they were tested. PMDD patients with high anxiety scores had similar levels of startle response during the first block of pulse-alone trials as lowanxiety PMDD patients. Likewise, PMDD patients with high depression and high anxiety/high depression scores did not differ in startle response from low depression or low anxiety/low depression patients, respectively, during the first block.

\section{Prepulse Inhibition (PPI)}

The three-way ANOVA indicated a significant groupphase $\times$ prepulse intensity interaction $\mathrm{F}(1,47)=5.17$; $p<0.05$ (Figure 2). Follow-up two-way ANOVAs indicated that PMDD patients exhibited lower levels of PPI compared 


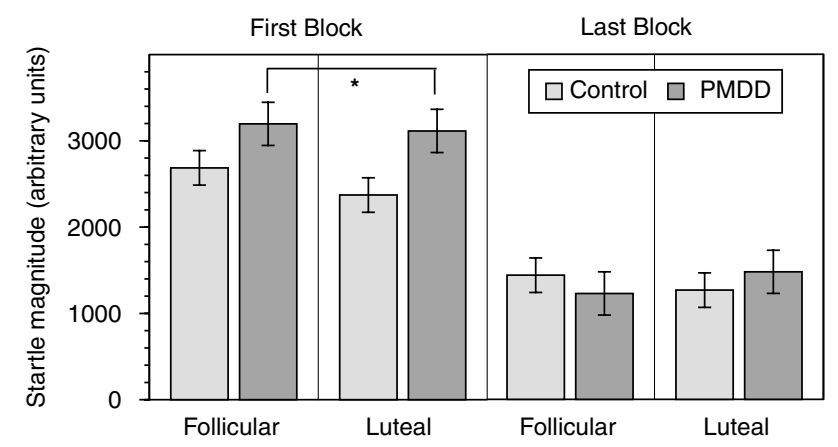

Figure I Mean \pm SEM startle amplitude during the first and last block of the test sessions in the follicular (a) and luteal (b) phases of the menstrual cycle in 27 women with premenstrual dysphoric disorder (PMDD) and 27 controls. Startle reactivity to the first block of pulse-alone trials was increased among PMDD patients in both phases of the menstrual cycle, $p<0.05$.

to control subjects in the luteal (group $\times$ prepulse intensity $\mathrm{F}(1,49)=10.81 ; p<0.01)$ but not the follicular phase. Posthoc $t$-tests revealed deficient luteal phase PPI in PMDD patients with $78 \mathrm{~dB}$ and $86 \mathrm{~dB}$ prepulses, $p<0.05$, respectively (Figure 2).

The group $\times$ phase $\times$ prepulse intensity interaction was also driven by an increase in PPI across the menstrual cycle among control subjects (phase by prepulse intensity interaction $\mathrm{F}(1,22)=4.58 ; p<0.01$ ), whereas PPI magnitude remained unchanged in PMDD patients between cycle phases (main effect of phase $F(1,24)=0.84$ ).

The magnitude of PPI was a function of the anxiety symptoms experienced by the PMDD patients during the luteal phase in which they were tested. PMDD patients with high luteal anxiety scores had significantly lower levels of PPI compared to PMDD patients with lower levels of anxiety, $\mathrm{F}(1,20)=8.87 ; p<0.01$ (main effect of group) (Figure 3).

The degree of depressive symptoms experienced by the PMDD patients did not affect PPI. PMDD patients with high depression scores had similar levels of PPI compared to PMDD patients with lower levels of depression.

However, PMDD patients with high anxiety/high depression had significantly lower levels of PPI compared to patients with low anxiety/low depression scores, $\mathrm{F}(1,15)=7.57 ; p<0.05$ (main effect of group).

\section{Correlations between estradiol, progesterone, startle response, and mean PPI}

There were no significant correlations between estradiol, progesterone, startle response, and mean PPI in either group or cycle phase.

\section{DISCUSSION}

Using objective measures of physiological arousal and sensorimotor gating, we demonstrated that PMDD patients have increased startle reactivity across both menstrual cycle phases and lower levels of PPI 7during the late luteal phase compared to asymptomatic controls. Furthermore, PMDD patients with high anxiety levels as well as patients with

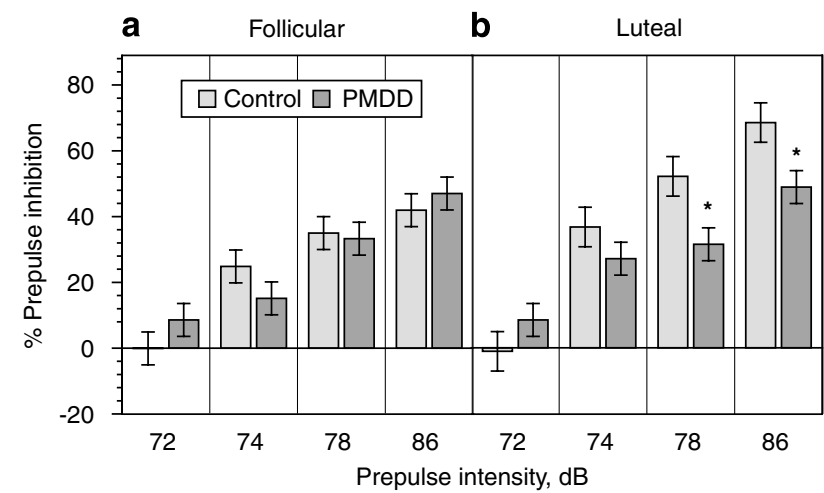

Figure 2 Mean \pm SEM percent prepulse inhibition by trial type in the follicular (a) and luteal (b) phases of the menstrual cycle in 27 women with premenstrual dysphoric disorder (PMDD) and 27 controls. PPI $=72 \mathrm{~dB}$; $\mathrm{PP} 2=74 \mathrm{~dB} ; \mathrm{PP} 3=78 \mathrm{~dB}$; and PP4 $=86 \mathrm{~dB}$. PMDD patients exhibited lower levels of prepulse inhibition (PPI) with $78 \mathrm{~dB}$ and $86 \mathrm{~dB}$ prepulses compared to control subjects in the luteal phase of menstrual cycle $(p<0.01)$. PPI magnitude increased across the menstrual cycle among control subjects $(p<0.0 \mathrm{I})$, but remained unchanged between cycle phases in PMDD patients.

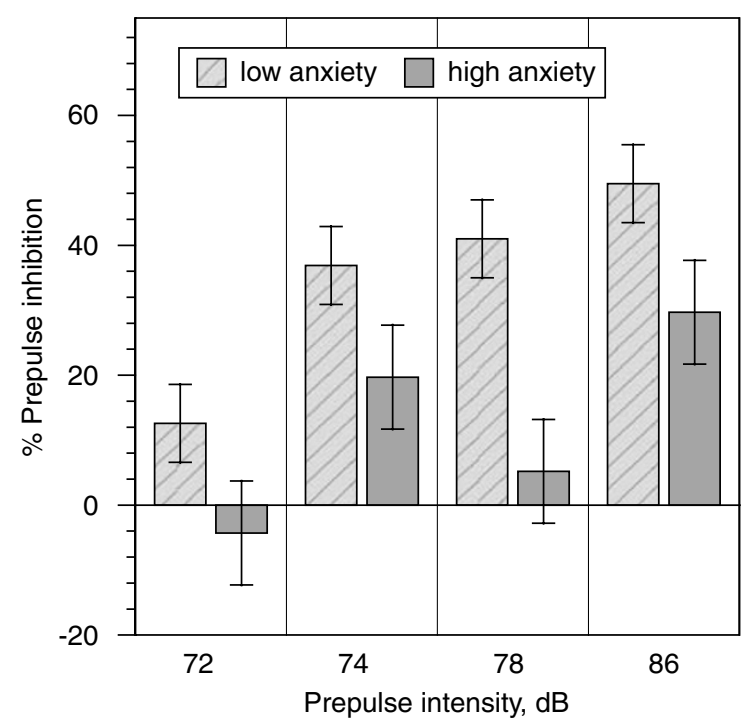

Figure 3 Mean \pm SEM percent prepulse inhibition by trial type in luteal phases of the menstrual cycle in 22 women with premenstrual dysphoric disorder (PMDD). $\mathrm{PPI}=72 \mathrm{~dB} ; \mathrm{PP} 2=74 \mathrm{~dB} ; \mathrm{PP} 3=78 \mathrm{~dB}$; and $\mathrm{PP} 4=$ $86 \mathrm{~dB}$. PMDD patients with high luteal anxiety scores had significantly lower levels of prepulse inhibition (PPI) compared to PMDD patients with lower levels of anxiety, $p<0.01$.

both high anxiety and high depression levels had even more impaired PPI than less symptomatic patients. PMDD patients did not demonstrate habituation deficits in the luteal phase, compared to either their own follicular phase or to controls in the luteal phase.

Recently, Epperson et al (2007) demonstrated that PMDD patients have an increased baseline startle response during the luteal phase compared to the follicular phase. We had hypothesized that PMDD patients would display increased startle response compared to control subjects only in the luteal phase. One reason why menstrual cycle effects in 
startle response were not detected in our sample could be that tests were scheduled to coincide with minimum (midfollicular phase) and maximum (late luteal phase) PMDD symptomatology, rather than to coincide with the most different hormonal situations obtainable during the menstrual cycle (ie early follicular phase $v s$ mid-luteal phase) (Epperson et al, 2007). Although we chose these time points for valid reasons, more stringent timing criteria may have reduced variability and increased the possibility of detecting changes in startle response across the menstrual cycle in PMDD patients.

Clearly progesterone or its metabolite allopregnanolone, and time-course and timing of exposure to progesterone, are able to influence startle response although their respective contributions have not been fully elucidated. Withdrawal from progesterone has been reported to increase baseline startle response (Gulinello et al, 2003; Gulinello and Smith, 2003), whereas allopregnanolone attenuates CRH-enhanced startle response and medroxyprogesterone acetate, acting via the progesterone receptor, has been shown to amplify CRH-enhanced startle response (Toufexis et al, 2004).

According to our study findings, increased startle response rather appears to be a trait phenomenon in PMDD patients, suggesting an underlying hypersensitivity in the systems involved in the startle reflex at all times. This vulnerability trait could, in concert with other factors, contribute to the appearance of PMDD symptoms during the luteal phase when estradiol and progesterone levels are high or decreasing.

PMDD patients had lower levels of PPI in the late luteal phase compared to control subjects. This difference was mainly driven by the fact that the PPI increased in the late luteal phase of control subjects but did not do so equivalently in PMDD subjects, ie PMDD patients failed to display normal changes in PPI across the menstrual cycle.

Patients with schizophrenia (Braff et al, 2001; Ludewig et al, 2003; Swerdlow et al, 2006), OCD (Hoenig et al, 2005), PTSD (Grillon et al, 1998), and panic disorder (Ludewig et al, 2002) have deficits in PPI. Across disorders, PPI deficits have been associated with perceptual abnormalities, increased anxiety, and difficulty inhibiting intrusive thoughts (Braff et al, 2001). PPI is also affected by gender and ovarian steroids. While no gender-related differences in PPI have been reported during the follicular phase of the menstrual cycle, prior studies have indicated that women have impaired PPI compared to men in the mid-luteal phase (Jovanovic et al, 2004; Swerdlow et al, 1997). Also, PPI varies across the menstrual cycle with reduced PPI in the mid-luteal phase compared to early or mid-follicular phases (Jovanovic et al, 2004; Swerdlow et al, 1997).

In PMDD patients, PPI deficits were only evident during their symptomatic period, ie during the late luteal phase, whereas during the follicular phase when subjects are devoid of symptoms no difference in PPI between PMDD patients and control subjects was found. PMDD patients are reported to be more sensitive to the CNS effects of ovarian steroids (Schmidt et al, 1998), and while ovarian steroid hormones have an important role in sensorimotor gating, it is thus not surprising that PPI is affected in these patients. Furthermore, PMDD patients with high anxiety levels and those with both high anxiety and high depression levels during the luteal phase had even more impaired PPI than less symptomatic patients. As variable hormone levels from menstrual cycle to menstrual cycle within individual subjects may result in variable symptom expression (Hammarback et al, 1989; Wang et al, 1997), this finding underlies the assumption that the hormonal events that trigger PMDD symptoms in a specific menstrual cycle could also affect the circuits modulating PPI.

In our study, control subjects demonstrated increased PPI in the late luteal phase compared to the mid-follicular phase, whereas PPI of PMDD patients remained unaltered across cycle phases. This finding in control subjects, which is in contrast with previous studies of menstrual cycle effects on PPI (Jovanovic et al, 2004; Swerdlow et al, 1997), is most likely due to the fact that subjects were tested in relation to symptom severity rather than when differences in PPI would be most evident (Swerdlow et al, 1997).

The underlying mechanisms of ovarian steroid actions leading to PMDD symptoms have not been elucidated unequivocally. However, several lines of evidence suggest that progestin-induced alteration of the GABAergic system is one of the primary factors in the development of anxiety, depression, and PMDD (Epperson et al, 2002; Sundstrom et al, 1998, 1997a, b). This hypothesis is plausible because progesterone can be metabolized to GABA-active neurosteroids, such as allopregnanolone, which bind to the $\mathrm{GABA}_{\mathrm{A}}$ receptor. Acutely, allopregnanolone enhances inhibitory neurotransmission (Majewska et al, 1986), thus exerting anxiolytic (Akwa et al, 1999; Bitran et al, 1991, 1993), sedative (Lancel et al, 1997; Timby et al, 2006), and antiepileptic effects (Landgren et al, 1998).

However, the homeostatic response of the GABAergic system to prolonged exposure and/or withdrawal from progesterone and allopregnanolone results in profound changes in the regulation of fast inhibitory neurotransmission, similarly to what occurs after prolonged exposure and withdrawal from conventional GABA-modulatory drugs (Gallo and Smith, 1993; Smith et al, 1998a, b). Furthermore, changes in sensitivity to GABA-modulatory agents, including neurosteroids, across the menstrual cycle have been reported in PMDD patients. For instance, assessing sedation with saccadic eye velocity as an independent measure, patients with PMDD have been reported to have a decreased responsiveness to pregnanolone (a stereoisomer to allopregnanolone) and benzodiazepines (Sundstrom et al, 1998, 1997a,b), similar to findings in female rats during progesterone withdrawal (Moran and Smith, 1998; Smith et al, 1998a). As sensorimotor gating is regulated by $\mathrm{GABA}_{\mathrm{A}}$ receptors in the amygdala and the BNST, it is plausible that progesterone, or its neuroactive metabolites, is responsible for both symptom provocation and disruption of PPI in PMDD patients (Davis, 1980; Davis et al, 1994; Lee and Davis, 1997).

However, estradiol cannot be ruled out as a symptomprovoking factor in PMDD (Schmidt et al, 1991; Seippel and Backstrom, 1998), and changes in estradiol serum concentrations might be equally important for the impaired PPI found during the late luteal phase in our PMDD patients. Both estrogen receptors $(\alpha$ and $\beta$ ) are found in the nucleus accumbens and amygdala (Shughrue et al, 1997) and could mediate the effects of estrogen on PPI. Estrogen treatment in ovariectomized female rats has been reported to prevent 
8-OH-DPAT-induced disruptions of PPI (Gogos and Van den Buuse, 2004), and similar findings have also been obtained in females where estrogen treatment prevented buspirone-induced PPI deficits (Gogos et al, 2006). However, treatment with $2 \mathrm{mg}$ estradiol during the early follicular phase did not affect PPI in healthy women, (Gogos et al, 2006). Together with the unexpected finding of a dose-dependent increase in PPI in ovariectomized rats following estrogen treatment (Van den Buuse and Eikelis, 2001), it must be assumed that combined effects of estradiol and progesterone are responsible for the disrupted PPI noted in our PMDD patients.

In conclusion, this study has indicated that patients with PMDD have an increased startle response during both phases of the menstrual cycle. The study has also indicated that PMDD patients fail to display normal changes in PPI across the menstrual cycle, which results in disrupted PPI during their most symptomatic period.

Thus, PMDD patients display not only increased physical arousal but also failure in systems which may be designed to mitigate combinations of negative stimuli.

\section{ACKNOWLEDGEMENTS}

This study was supported by grants from the Astrid Karlsson Foundation, the Tore Nilsson Foundation, Family Planning Foundation Uppsala, Magnus Bergwall Foundation, and The Swedish Society of Medicine.

\section{FINANCIAL DISCLOSURES}

M. Geyer holds an equity interest in San Diego Instruments, receives support from the U.S. Veterans Administration VISN 22 MIRECC and NIH grant MH42228, and over the past three years has received compensation from Abbott, Acadia, Addex, Amgen, AstraZeneca, Bristol-Myers Squibb, Jazz, Organon, Nura, San Diego Instruments, Serono, and Wyeth-Ayerst. None of the other authors have any conflicts to disclose.

\section{REFERENCES}

Akwa Y, Purdy RH, Koob GF, Britton KT (1999). The amygdala mediates the anxiolytic-like effect of the neurosteroid allopregnanolone in rat. Behav Brain Res 106: 119-125.

Allen NB, Trinder J, Brennan C (1999). Affective startle modulation in clinical depression: preliminary findings. Biol Psychiatry 46: 542-550.

Backstrom T, Andreen L, Birzniece V, Bjorn I, Andersson I-M, Nordenstam-Haghjo $M$ et al (2003). The role of hormones and hormonal treatments in premenstrual syndrome. CNS Drugs 17: 325-342.

Bitran D, Hilvers RJ, Kellogg CK (1991). Anxiolytic effects of 3 alpha-hydroxy-5 alpha[beta]-pregnan-20-one: endogenous metabolites of progesterone that are active at the GABAA receptor. Brain Res 561: 157-161.

Bitran D, Purdy RH, Kellogg CK (1993). Anxiolytic effect of progesterone is associated with increases in cortical allopregnanolone and GABAA receptor function. Pharmacol Biochem Behav 45: 423-428.

Bjorn I, Bixo M, Nojd KS, Collberg P, Nyberg S, SundstromPoromaa I et al (2002). The impact of different doses of medroxyprogesterone acetate on mood symptoms in sequential hormonal therapy. Gynecol Endocrinol 16: 1-8.

Bjorn I, Sundstrom-Poromaa I, Bixo M, Nyberg S, Backstrom G, Backstrom $T$ (2003). Increase of estrogen dose deteriorates mood during progestin phase in sequential hormonal therapy. J Clin Endocrinol Metab 88: 2026-2030.

Braff DL, Geyer MA, Swerdlow NR (2001). Human studies of prepulse inhibition of startle: normal subjects, patient groups, and pharmacological studies. Psychopharmacology (Berl) 156: 234-258.

Byrnes EM, Bridges RS, Scanlan VF, Babb JA, Byrnes JJ (2007). Sensorimotor gating and dopamine function in postpartum rats. Neuropsychopharmacology 32: 1021-1031.

Davis M (1980). Neurochemical modulation of sensory-motor reactivity: acoustic and tactile startle reflexes. Neurosci Biobehav Rev 4: 241-263.

Davis M, Rainnie D, Cassell M (1994). Neurotransmission in the rat amygdala related to fear and anxiety. Trends Neurosci 17: 208-214.

Davis M, Walker DL, Lee Y (1997). Roles of the amygdala and bed nucleus of the stria terminalis in fear and anxiety measured with the acoustic startle reflex. Possible relevance to PTSD. Ann NY Acad Sci 821: 305-331.

Epperson CN, Haga K, Mason GF, Sellers E, Gueorguieva R, Zhang W et al (2002). Cortical gamma-aminobutyric acid levels across the menstrual cycle in healthy women and those with premenstrual dysphoric disorder: a proton magnetic resonance spectroscopy study. Arch Gen Psychiatry 59: 851-858.

Epperson CN, Pittman B, Czarkowski KA, Stiklus S, Krystal JH, Grillon C (2007). Luteal-phase accentuation of acoustic startle response in women with premenstrual dysphoric disorder. Neuropsychopharmacology 32: 2190-2198.

Eriksson E, Alling C, Andersch B, Andersson K, Berggren U (1994). Cerebrospinal fluid levels of monoamine metabolites. A preliminary study of their relation to menstrual cycle phase, sex steroids, and pituitary hormones in healthy women and in women with premenstrual syndrome. Neuropsychopharmacology 11: 201-213.

Gallo MA, Smith SS (1993). Progesterone withdrawal decreases latency to and increases duration of electrified prod burial: a possible rat model of PMS anxiety. Pharmacol Biochem Behav 46: 897-904.

Gogos A, Nathan PJ, Guille V, Croft RJ, Buuse MV (2006). Estrogen prevents 5-HT(1A) receptor-induced disruptions of prepulse inhibition in healthy women. Neuropsychopharmacology 31: 885-889.

Gogos A, Van den Buuse M (2004). Estrogen and progesterone prevent disruption of prepulse inhibition by the serotonin-1A receptor agonist 8-hydroxy-2-dipropylaminotetralin. J Pharmacol Exp Ther 309: 267-274.

Grillon C, Morgan III CA, Davis M, Southwick SM (1998). Effects of experimental context and explicit threat cues on acoustic startle in Vietnam veterans with posttraumatic stress disorder. Biol Psychiatry 44: 1027-1036.

Gulinello M, Orman R, Smith SS (2003). Sex differences in anxiety, sensorimotor gating and expression of the alpha4 subunit of the GABAA receptor in the amygdala after progesterone withdrawal. Eur J Neurosci 17: 641-648.

Gulinello M, Smith SS (2003). Anxiogenic effects of neurosteroid exposure: sex differences and altered GABAA receptor pharmacology in adult rats. J Pharmacol Exp Ther 305: 541-548.

Hammarback S, Backstrom T (1988). Induced anovulation as treatment of premenstrual tension syndrome. A double-blind cross-over study with GnRH-agonist versus placebo. Acta Obstet Gynecol Scand 67: 159-166.

Hammarback S, Backstrom T, Holst J, von Schoultz B, Lyrenas S (1985). Cyclical mood changes as in the premenstrual tension syndrome during sequential estrogen-progestagen postmenopausal replacement therapy. Acta Obstet Gynecol Scand 64: 393-397. 
Hammarback S, Damber JE, Backstrom T (1989). Relationship between symptom severity and hormone changes in women with premenstrual syndrome. J Clin Endocrinol Metab 68: 125-130.

Hammarback S, Ekholm UB, Backstrom T (1991). Spontaneous anovulation causing disappearance of cyclical symptoms in women with the premenstrual syndrome. Acta Endocrinol (Copenh) 125: 132-137.

Hauser J, Rudolph U, Keist R, Mohler H, Feldon J, Yee BK (2005). Hippocampal alpha5 subunit-containing GABAA receptors modulate the expression of prepulse inhibition. Mol Psychiatry 10: 201-207.

Hoenig K, Hochrein A, Quednow BB, Maier W, Wagner M (2005). Impaired prepulse inhibition of acoustic startle in obsessivecompulsive disorder. Biol Psychiatry 57: 1153-1158.

Jovanovic T, Szilagyi S, Chakravorty S, Fiallos AM, Lewison BJ, Parwani A et al (2004). Menstrual cycle phase effects on prepulse inhibition of acoustic startle. Psychophysiology 41: 401-406.

Koch M (1999). The neurobiology of startle. Prog Neurobiol 59: 107-128.

Lancel M, Faulhaber J, Schiffelholz T, Romeo E, Di Michele F, Holsboer $\mathrm{F}$ et al (1997). Allopregnanolone affects sleep in a benzodiazepine-like fashion. J Pharmacol Exp Ther 282: 1213-1218.

Landgren S, Wang MD, Backstrom T, Johansson S (1998). Interaction between 3 alpha-hydroxy-5 alpha-pregnan-20-one and carbachol in the control of neuronal excitability in hippocampal slices of female rats in defined phases of the oestrus. Acta Physiol Scand 162: 77-88.

Lee Y, Davis M (1997). Role of the hippocampus, the bed nucleus of the stria terminalis, and the amygdala in the excitatory effect of corticotropin-releasing hormone on the acoustic startle reflex. J Neurosci 17: 6434-6446.

Ludewig K, Geyer MA, Vollenweider FX (2003). Deficits in prepulse inhibition and habituation in never-medicated, firstepisode schizophrenia. Biol Psychiatry 54: 121-128.

Ludewig S, Ludewig K, Geyer MA, Hell D, Vollenweider FX (2002). Prepulse inhibition deficits in patients with panic disorder. Depress Anxiety 15: 55-60.

Majewska MD, Harrison NL, Schwartz RD, Barker JL, Paul SM (1986). Steroid hormone metabolites are barbiturate-like modulators of the GABA receptor. Science 232: 1004-1007.

Moran MH, Smith SS (1998). Progesterone withdrawal I: proconvulsant effects. Brain Res 807: 84-90.

Morgan III CA, Grillon C, Southwick SM, Davis M, Charney DS (1996). Exaggerated acoustic startle reflex in Gulf War veterans with posttraumatic stress disorder. Am J Psychiatry 153: 64-68.

Parry BL (2001). The role of central serotonergic dysfunction in the aetiology of premenstrual dysphoric disorder: therapeutic implications. CNS Drugs 15: 277-285.

Pissiota A, Frans O, Michelgard A, Appel L, Langstrom B, Flaten MA et al (2003). Amygdala and anterior cingulate cortex activation during affective startle modulation: a PET study of fear. Eur J Neurosci 18: 1325-1331.

Plappert CF, Pilz PK (2002). Difference in anxiety and sensitization of the acoustic startle response between the two inbred mouse strains BALB/cAN and dBA/2N. Genes Brain Behav 1: 178-186.

Schmidt PJ, Nieman LK, Danaceau MA, Adams LF, Rubinow DR (1998). Differential behavioral effects of gonadal steroids in women with and in those without premenstrual syndrome. N Engl J Med 338: 209-216.

Schmidt PJ, Nieman LK, Grover GN, Muller KL, Merriam GR, Rubinow DR (1991). Lack of effect of induced menses on symptoms in women with premenstrual syndrome. $N$ Engl J Med 324: 1174-1179.

Schwegler H, Pilz PK, Koch M, Fendt M, Linke R, Driscoll P (1997). The acoustic startle response in inbred Roman high- and lowavoidance rats. Behav Genet 27: 579-582.

Seippel L, Backstrom T (1998). Luteal-phase estradiol relates to symptom severity in patients with premenstrual syndrome. J Clin Endocrinol Metab 83: 1988-1992.
Sheehan DV, Lecrubier Y, Sheehan KH, Amorim P, Janavs J, Weiller E et al (1998). The Mini-International Neuropsychiatric Interview (M.I.N.I.): the development and validation of a structured diagnostic psychiatric interview for DSM-IV and ICD-10. J Clin Psychiatry 59(Suppl 20): 22-33; quiz 34-57.

Shughrue PJ, Lane MV, Merchenthaler I (1997). Comparative distribution of estrogen receptor-alpha and -beta mRNA in the rat central nervous system. J Comp Neurol 388: 507-525.

Smith SS, Gong QH, Hsu FC, Markowitz RS, ffrench-Mullen JM, Li X (1998a). GABA(A) receptor alpha4 subunit suppression prevents withdrawal properties of an endogenous steroid. Nature 392: 926-930.

Smith SS, Gong QH, Li X, Moran MH, Bitran D, Frye CA et al (1998b). Withdrawal from 3alpha-OH-5alpha-pregnan-20-One using a pseudopregnancy model alters the kinetics of hippocampal GABAAgated current and increases the GABAA receptor alpha4 subunit in association with increased anxiety. J Neurosci 18: 5275-5284.

Stohr T, Szuran T, Pliska V, Feldon J (1999). Behavioural and hormonal differences between two Lewis rat lines. Behav Brain Res 101: 163-172.

Sundstrom I, Andersson A, Nyberg S, Ashbrook D, Purdy RH, Backstrom T (1998). Patients with premenstrual syndrome have a different sensitivity to a neuroactive steroid during the menstrual cycle compared to control subjects. Neuroendocrinology 67: 126-138.

Sundstrom I, Ashbrook D, Backstrom T (1997a). Reduced benzodiazepine sensitivity in patients with premenstrual syndrome: a pilot study. Psychoneuroendocrinology 22: 25-38.

Sundstrom I, Nyberg S, Backstrom T (1997b). Patients with premenstrual syndrome have reduced sensitivity to midazolam compared to control subjects. Neuropsychopharmacology 17: 370-381.

Sundstrom I, Nyberg S, Bixo M, Hammarback S, Backstrom T (1999). Treatment of premenstrual syndrome with gonadotropin-releasing hormone agonist in a low dose regimen. Acta Obstet Gynecol Scand 78: 891-899.

Swerdlow NR, Auerbach P, Monroe SM, Hartston H, Geyer MA, Braff DL (1993). Men are more inhibited than women by weak prepulses. Biol Psychiatry 34: 253-260.

Swerdlow NR, Hartman PL, Auerbach PP (1997). Changes in sensorimotor inhibition across the menstrual cycle: implications for neuropsychiatric disorders. Biol Psychiatry 41: 452-460.

Swerdlow NR, Light GA, Cadenhead KS, Sprock J, Hsieh MH, Braff DL (2006). Startle gating deficits in a large cohort of patients with schizophrenia: relationship to medications, symptoms, neurocognition, and level of function. Arch Gen Psychiatry 63: 1325-1335.

Timby E, Balgard M, Nyberg S et al (2006). Pharmacokinetic and behavioral effects of allopregnanolone in healthy women. Psychopharmacology (Berl) 186: 414-424.

Toufexis DJ, Davis C, Hammond A, Davis M (2004). Progesterone attenuates corticotropin-releasing factor-enhanced but not fearpotentiated startle via the activity of its neuroactive metabolite, allopregnanolone. J Neurosci 24: 10280-10287.

Toufexis DJ, Rochford J, Walker CD (1999). Lactation-induced reduction in rats' acoustic startle is associated with changes in noradrenergic neurotransmission. Behav Neurosci 113: 176-184.

Vaillancourt C, Cyr M, Rochford J, Boksa P, Di Paolo T (2002). Effects of ovariectomy and estradiol on acoustic startle responses in rats. Pharmacol Biochem Behav 74: 103-109.

Van den Buuse M, Eikelis N (2001). Estrogen increases prepulse inhibition of acoustic startle in rats. Eur J Pharmacol 425: 33-41.

Wang MD, Landgren S, Backstrom T (1997). The effects of allopregnanolone, pregnenolone sulphate and pregnenolone on the CA1 population spike of the rat hippocampus after 17 betaoestradiol priming. Acta Physiol Scand 159: 343-344.

Yee BK, Keist R, von Boehmer L et al (2005). A schizophreniarelated sensorimotor deficit links alpha 3-containing GABAA receptors to a dopamine hyperfunction. Proc Natl Acad Sci 102: 17154-17159. 